\title{
Job matching, unexpected obligations and retirement decisions
}

Received (in revised form): 30th July, 2008

\section{Mário Centeno}

completed his PhD in Economics in 2000 from Harvard University. Presently, he is with Banco de Portugal (Portugal Central Bank) and ISEG/ Universidade Técnica de Lisboa, Portugal. His research interests include labour economics and job search theory. His recent publications include 'Tenure, business cycle and the wage setting process', European Economic Review, 2006, Vol. 50, No. 2, pp. 401-424; 'The impact of unemployment insurance generosity on match quality distribution', Economics Letters, 2006, Vol. 93, No. 2, pp. $235-241$.

\section{Márcio V. Corrêa}

completed his PhD in Economics in 2007 from ISEG/Universidade Técnica de Lisboa. Presently, he is with CAEN/Universidade Federal do Ceará, Brazil. His research interests include labour economics and job search theory. His recent research includes 'Job matching, technological progress and worker-provided on-the-job training'.

\begin{abstract}
Our objective is to investigate the effect of unexpected changes in worker financial obligations on retirement decisions. We considered throughout this paper that a firm is unable to determine the right moment in which a particular worker should retire. We found that wage rates decrease when a worker obtains the right to retire and that retirement benefits should be more attractive than the unemployment insurance in order to have workers migrating from unemployment to retirement, while retirement benefits do not need to be higher than wages to have worker flows from employment to retirement. We also verified that the more difficult it gets to obtain the right to retire, the higher the job creation flow shall be and that worker reservation obligations have an ambiguous effect on retirement rates.
\end{abstract}

Pensions (2008) 13, 159-166. doi:10.1057/pm.2008.14

Keywords: job creation, job destruction, retirement decisions

\section{Introduction}

The argument that if nothing is done, retirement programmes will go through serious financial problems in a not so distant future has been a common one. The idea is that the combination of low fertility rates and increased life expectancy has led to population aging, risking the maintenance of social security programmes. There are also, however, other reasons proposed in the literature, not merely demographic ones, which are important for optimal rule determination in

Correspondence: Mário Centeno, Banco de Portugal, Av. Almirante Reis, 716, Lisbon 1150-012, Portugal.

Tel: +351213130837

Fax: + 351213130837

E-mail: Mario.Centeno@bportugal.pt worker retirement and also affect the continuity of these programmes. Another reason, probably the most often mentioned in recent years, is the quality of retirement systems. ${ }^{1,2}$

The usual argument is that the facility to obtain retirement rights, together with the attractiveness of received benefits, increases the relative cost for the worker to remain in the market, thus making retirement easier.

Other explanations mentioned in the literature are employability rate reductions, human capital obsolescence, discrimination, health problems, leisure preferences and long unemployment periods or inactivity that makes it more difficult for the worker to remain in the labour force, due to the high cost that these factors impose on the worker in regards to retirement rights, and when 
not retired, in postponing his retirement decision. $^{3-7}$

If we add to these previous problems the fact that instead of being in a capital accumulation process, we now observe an increase in individual debts, a phenomenon that can be explained by the fact that we are experiencing periods of considerable economic turbulence, ${ }^{8,9}$ meaning higher chances of unexpected events. So we can understand the reason why this issue is so important nowadays.

According to Banco de Portugal's ${ }^{10}$ Financial Stability Report, the difference between individual debts and assets has increased, not only at a historical level but also internationally. Reductions in debt costs and increases in family income in recent years have been the major causes for this process. The consequences of this individual behaviour are a threat for social security programmes due to the high level of worker dependence on government benefits.

In this paper, we approach the impact of personal financial obligations on optimal retirement decisions. Our interest is to evaluate how unexpected changes on individual financial obligations affect the worker best rule for leaving the labour force. In other words, we will consider that there are events that alter worker's obligation levels - an unexpected debt, for example - changing dependency levels on employed/unemployed status to the detriment of retirement, which causes changes in the optimal moment to exit the labour force. ${ }^{11-13}$

We can observe that such a simple approach generates interesting results, for example, that worker wage rates diminish when they obtain the right to retire; that the retirement pension must be higher than unemployment benefits for workers to move from unemployment to retirement, while the retirement pension does not have to be higher than the wage rate to encourage worker flows from unemployment to retirement. Higher probabilities of retirement decisions imply lower worker wage rates and new job creation dynamics. Besides, as obtaining retirement rights becomes easier, the job creation flow decreases and worker obligation reservations generate an ambiguous effect on retirement rates, while unemployed worker obligation reservations generate unambiguous effects on retirement rates. Some authors have already investigated the effects of unexpected events on retirement incentives. ${ }^{12,14-16}$ No one, however, has approached the problem of unexpected changes in worker obligations affecting optimal retirement decision rule in an imperfect labour market. ${ }^{17}$

Bhattacharya et al. ${ }^{18}$ have also approached the topic of optimal retirement policy in an environment of search frictions. Although the present model has some similarities with this one, these authors only consider the flow of workers from employment to retirement, while we consider flows from both employment and unemployment to retirement. ${ }^{6,19}$ Another difference between the two models is that our goal is to investigate effects of worker obligations on retirement decisions, while Bhattacharya et al. focus on the effects of retirement programme features on the best rule for exiting the labour market.

Another investigation that follows these guidelines was developed by Gordon and Blinder, ${ }^{20}$ who estimate the relative importance of various factors - health, wage rates, preferences, and public and private retirement system incentives - on retirement decisions. The greatest similarity lies on reservation wage determination. One of the differences, however, is that we also seek to determine reservation unemployment benefit, that is, the unemployment benefit of indifference between the options of retirement and unemployment.

\section{Theoretical model}

The basic hypothesis behind the proposed model is that higher financial obligations result in lower retirement chances. ${ }^{5,21}$ In this section, we will develop a theoretical model to evaluate additional effects of this worker strategy.

Suppose that the economy is composed of a constant population of workers who live infinitely and a large number of firms. Workers and firms match to perform a productive activity. Every 
worker has the right to retire. ${ }^{22}$ Firms and workers are risk-neutral and discount the future at the exogenous and constant rate $r$.

Before production starts, firms and workers are involved in a search process to find a partner, where $c$ represents firm searching costs. Occupied jobs produce $x$ at each moment of time and can be destroyed due to an idiosyncratic shock that follows a Poisson process with arrival rate $\lambda$. The number of job matches formed per period is given by a degree one, non-negative, concave and homogeneous function, which increases in both arguments $m(v, u)$, where $v$ represents vacancy rate and $u$ the fraction of unemployed workers in the economy.

Unemployed workers move to the employed status at a rate $\theta q(\theta)$, while a job vacancy is filled at rate $q(\theta)$, where $(\theta)$ represents the ratio of $v$ and $u$.

Each firm has only one job position, which can be empty or filled, while each worker can be retired (having decided to retire), unemployed or employed in only one job position per period. Workers can retire immediately or postpone this decision at no cost. Suppose that this decision depends only on the exogenous level of worker obligation, $o$. Once a worker decides to retire he/she cannot re-enter the labour market.

At any given moment there may be a change in worker obligation, determined by a general distribution $G(o)$, defined in the unit interval. Suppose that $o$ affects employment and unemployment values in a positive way and firms do not know the level of worker obligations or the effects of such obligations on their retirement decisions, considering that they move into retirement at a rate $\varphi .5,23,24$

We are therefore considering that there are events that change worker dependency level on employed or unemployed statuses, postponing labour force exit and that firms do not take these events into account, considering that workers retire at a rate $\varphi$.

Let $S$ and $T$ represent reservation obligations of employed and unemployed workers, respectively. Suppose that $V$ and $J$ represent both vacant and filled position values for a firm, while $U, W$ and $R$ represent unemployment, employment and retirement values for the worker, respectively. Accordingly, value functions for the firm and the worker are given by:

$$
\begin{gathered}
r V=-c+q(\theta)[J-V] \\
r U=\operatorname{Max}\{z+\theta q(\theta)[W-U] ; r R-o\} \\
r R=y-d R \\
r W=\operatorname{Max}\{w-\lambda[W-\operatorname{Max}(U, R)] ; r R-o\} \\
r J=x-w-\lambda[J-V]-\varphi[J-V]
\end{gathered}
$$

where $z$ represents unemployment insurance benefits, $y$ stands for retirement benefits, $d$ is the rate at which a retired worker abandons this status and $w$ represents the worker wage rate.

Expression (1) tells us that a firm with a vacant position has a search cost $c$ per period. With a probability $q(\theta)$, this vacant position can be filled.

Expression (5) tells us that the filled position produces $x$ and pays $w$, the wage per period. This filled position is destroyed due to an idiosyncratic shock $\lambda$ and the worker exits the labour market with probability $\varphi$.

The third equation tells us that once retired, the worker receives $y$ and has a probability $d$ of abandoning this status.

The second expression tells us that the unemployed worker makes an optimal decision between remaining in the labour market, receiving $z$ as net benefit (deducting obligations) and finding employment with probability $\theta q(\theta)$, and moving to the retirement status.

Finally, expression (4) tells us that the employed worker chooses between remaining employed, with a remuneration compatible with his/her obligations equal to $w$ and with a probability $\lambda$ loses his/her job, inducing the 
worker to decide between remaining in the labour market or retiring.

We can see from these expressions and the above assumptions about $S$ and $T$ that workers evaluate employment and unemployment options according to their obligations. Thus, whenever $o>S(0>T)$, the employed (unemployed) worker postpones retirement. In turn, whenever $o \leqslant S(o \leqslant T)$, the employed (unemployed) worker decides to retire. Observe that once the retirement decision is postponed, the worker remains in the labour force until his/her obligation is reduced to a value below $S$ or $T$.

Also notice from the previous expressions that we are modelling a condition where workers evaluate their options from a different perspective than that of firms, which are unaware of this peculiarity. ${ }^{25}$

Accepting the usual hypothesis of free entrance, we have from (1) that

$$
J=\frac{c}{q(\theta)}
$$

Thus, there is job creation up to the point that the value of a new job matching equals the cost of occupying a vacancy, expressed in terms of the rate at which this position becomes occupied.

If the surplus generated by the match is divided according to the Generalised Nash Bargaining Solution, then the wage rate satisfies

$$
\beta[J-V]=(1-\beta)[W-\operatorname{Max}[U, R]]
$$

Observe from previous expressions that the surplus generated by the worker and the firm depends on worker unemployment and retirement options. If the unemployment option is stronger than retirement, reform rights stop being feasible in the bargaining process. Thus, once the productive partnership is broken, the worker shall never exercise his/her reform rights, since remaining unemployed generates higher returns, if compared to the profits obtained by leaving the labour market. Using expressions (1)-(7), the wage rate is given by

$$
\begin{array}{ll}
w=\beta\left[x-\frac{\varphi c}{q(\theta)}\right]+(1-\beta) \frac{y}{(r+d)}, & \text { if } R \geq U \\
w=\beta\left[x+c \theta-\frac{\varphi c}{q(\theta)}\right]+(1-\beta) z, & \text { if } R<U
\end{array}
$$

Notice that they are both composed of two terms. In the first expression, the first term is related to the worker productivity in his/her current job and expected search costs, considering the worker retirement decision, the second term is related to retirement benefits. In the second expression, the first term is related to the worker productivity in his/her current job, average search costs and expected search costs, considering the worker retirement decision, the last term is related to unemployment insurance benefits.

One of the advantages of studying obligation effects on labour force exit rule in an imperfect labour market is that worker's wages depend on his/her search costs and outside options, contrary to a competitive scenario, where worker's remuneration is equivalent to his/her productivity.

Observe that these expressions do not depend on the worker's obligations. This follows from the fact that firms ignore their effects on retirement, worker's wage rate diminishes with the right to retire, ${ }^{26-28}$ and higher retirement probabilities perceived by the firm result in lower wage rates. ${ }^{29}$

Also according to the first expression, a larger production generated by the job matching, the retirement benefits, the worker's bargaining power and the market tightness will result in higher worker's wage rate.

The wage rate increases with market tightness reductions because the firm deducts from the worker's wage rate the impact that his/her retirement generates for the firm (search costs to find another unemployed worker). The higher the market tightness, the easier it is for a firm with a vacancy to find an unemployed worker, which shall result in wage penalisation and higher worker exit rates. 
Continuing with the equilibrium characterisation, suppose that

$$
z(o)=z+o
$$

and

$$
w(0)=w+O
$$

represent wages and unemployment benefits compatible with employed and unemployed worker obligations, respectively.

Using this definition, suppose that (2) and (4) are given by

$$
\begin{gathered}
r U(o)=\operatorname{Max}\{z(o)+\theta q(\theta)[W(o)-U(o) ; r R\} \\
r W(o)=\operatorname{Max}\{w(o)-\lambda[W(o)-\operatorname{Max}[U(o), R]], r R\}
\end{gathered}
$$

At the indifference levels $S$ and $T$, we have that

$$
W(S)=R
$$

and

$$
U(T)=R
$$

then, evaluating (11) and (12) at $T$ and $S$ together with expression (3), we have that

$$
w(S)=\frac{r y}{(d+r)}+\frac{\beta \lambda_{c}}{(1-\beta) q(\theta)}
$$

and

$$
z(T)=\frac{r y}{(d+r)}-\frac{\beta c \theta}{(1-\beta)}
$$

represent the wage rate and unemployment insurance benefits compatible with indifference obligation.

Note that expressions (15) and (16) tell us that there is a $w(S)(z(T))$ that makes workers indifferent between the employment and retirement (unemployment and retirement) options.
Observe in (15) that as $\gamma, r, \beta, \lambda$ and $\theta$ are higher or $d$ is lower, workers shall expect to receive higher wages, considering their obligations, in order to be indifferent between retiring or not. Therefore, we can expect economies with more generous retirement benefits, or higher $\theta$, to experience higher worker flows from employment to retirement. ${ }^{30-32}$ In turn, we have from (16) that larger $\gamma$ and $r$ values or lower $d, \theta$ and $\beta$, will result in greater unemployment insurance benefits in order to make the worker indifferent between unemployment and retirement options.

The retirement option increases with market tightness reductions, basically because firms deduct the effects that retirement generates for them from worker's wages (search costs to find another unemployed worker). Hence, a higher $\theta$ means lower incentives to postpone retirement for the worker. Now, as we consider that if indifferent, the worker decides to retire, then whenever the wage rate and unemployment benefits compatible with worker obligations are given by (15) and (16), the employed and the unemployed worker shall decide to leave the labour market. On the other hand, if the wage rate (unemployment insurance benefits) compatible with worker obligations is higher than $w(S)(z(T))$, the worker will postpone retirement.

Proposition 1 It is necessary that $y>z(0)$, in order to have workers moving from unemployment to retirement. In turn, it is not necessary that $y>w(0)$ to observe worker flows from employment to retirement.

Proof We only need to use (15) and (16) and consider a general level of obligations to demonstrate Proposition 1.

The previous proposition tells us that in order to have workers migrating from unemployment to retirement, besides considering the term related to unemployment insurance benefits, it is necessary to compensate unemployed workers with an amount related to the gains that they obtain by finding a new vacancy and moving into the 
employed status. Thus, if unemployed workers are not correctly compensated, they will not be motivated to exercise their retirement rights.

The same cannot be said about employed workers because even reducing retirement pensions to an amount below $w(o)$ may not be enough to eliminate the flow of workers from employment to retirement.

One of the reasons for this previous effect is that the best paid workers tend to buy more leisure. Another argument used in the literature is that due to decreasing income marginal utility, wealthier workers put a lower value on extra income than poorer or unemployed ones.

Having determined retirement dynamics in regards to worker obligations, we will now see the optimal job creation rule. From expression (5), we have that

$$
[r+\lambda+\varphi] \frac{c}{q(\theta)}=x-w
$$

In this case, we have that higher retirement rates (in the firm's perspective) result in lower job creation rates and that an older labour force (closer to obtaining retirement rights) will imply lower job creation dynamics. Observe also that higher levels of $r, \lambda, c$ and $x$, or lower $w$ levels mean a poorer job creation rate.

Another thing that we can observe is that if $\varphi$ is higher than the rate at which the worker effectively requests his right to retire, it will imply a reduction in the flow of job creation when compared to the model where $G(S)=\varphi$. Thus, ignoring the exact rate at which the worker moves to retirement could severely penalise job creation dynamics.

Now, supposing that $b$ measures the rate at which workers enter the labour force, ${ }^{33}$ so that unemployment rate dynamics are given by

$$
\dot{u}=\lambda[1-G(T)](1-u-a)+b-\theta q(\theta) u-G(T) u
$$

where the first term on the right-hand side represents the flow of workers who move to unemployment due to an idiosyncratic shock, the second term represents the number of workers who enter the labour market via unemployment, the third term represents the number of unemployed workers who gain employment status and the last term gives the number of unemployed workers who retire.

Now, as in the steady state $\dot{u}=0$, then

$$
u=\frac{\lambda[1-G(T)](1-a)+b}{\lambda[1-G(T)]+\theta q(\theta)+G(T)}
$$

represents the equilibrium unemployment rate. Observe that if the number of new unemployed workers grows or if the probability for unemployed workers to retire falls, the result will be an increase in the equilibrium unemployment rate.

The idea behind this latter effect is that a lower $T$ implies more chances for an unemployed worker to decide against his/her right to retire, thus increasing the unemployment rate. On the other hand, higher market tightness or higher retirement rates shall result in a lower unemployment equilibrium rate.

Continuing the equilibrium characterisation, we have that

$$
\dot{a}=G(T) u+G(S)(1-u-a)-d a+\lambda G(T)(1-u-a)
$$

is the expression that determines the retirement equilibrium rate. The first term on the right-hand side gives us the number of retiring unemployed workers, the second gives us the number of employed workers who decide to retire, the third represents the number of retired workers who leave this status and the last one represents the number of workers who retire due to an idiosyncratic shock.

Also considering the steady-state condition, we have that

$$
a=\frac{[G(S)+\lambda G(T)]+u[(1-\lambda) G(T)-G(S)]}{G(S)+d+\lambda G(T)}
$$

gives us the equilibrium retirement rate.

We can observe from this expression that whenever $G(S)>(1-\lambda) G(T)$, the increase in the equilibrium unemployment rate comes with a decrease in the retirement rate. In turn, if 
$G(S)<(1-\lambda) G(T)$, we will have the opposite effect.

It is worth noting that if $S>T$, the equilibrium unemployment rate generates an ambiguous effect on worker retirement flow rates. This happens because higher unemployment corresponds to lower chances for an unemployed worker to find a vacancy and gain employment status, thus increasing retirement probabilities. However, as $S>T$, there will be a higher flow of employed workers leaving labour force and retiring, which increases the chances for an unemployed worker to become employed. Anderson et al. ${ }^{12}$ verified that the latter effect is dominant in the United States.

Increases in $G(S)$ will be followed by a retirement rate growth whenever $(1-u) d>u G(T)$, while if $(1-u) d<u G(T)$, we will have the opposite effect. In turn, increases in $d$ and decreases in $G(T)$ will be accompanied by reductions in $a$.

Proposition 2 Job creation conditions (17) and job destruction conditions (15) solely determine equilibrium values of $\theta$ and $w(S)$.

Proof As job destruction implies an increase in $\theta-w(S)$ space, while job creation does not depend on $w(S)$, the equilibrium exists and is unique. Knowing equilibrium values of $\theta$ and $w(S)$, expressions (8), (16), (19) and (21) determine equilibrium values of $w, z(T), u$ and $a$, respectively.

Now observe that the main characteristics of the model are obtained from the expressions that determine job creation and job destruction dynamics, unemployment and retirement rates. An improvement in retirement benefits, for example, will be followed by increases in $w(S)$, $z(T)$ and no changes in job creation dynamics. Now, as $G(S)$ and $G(T)$ grow, the overall effect on unemployment and retirement rates will depend on the magnitude of these two movements.

Also notice that increases in $\varphi$ imply reductions in $\theta$. Now, as $\theta$ decreases, we will again have two issues affecting unemployment and retirement rates. On the one hand, the reduction in $w(S)$ comes with a decrease in $a$, due to lower employed worker migration to retirement and an increase in $u$. But on the other hand, the increases in $z(T)$ result in an a growth, due to higher unemployed worker retirement rate and a reduction in $u$. The overall effect will depend on these two opposite effects.

\section{Conclusions}

The main goal of this paper was to study the effects of higher obligation levels on optimal worker retirement decisions.

We saw that in an environment with search frictions, worker wage rates diminish with the right to retire. We also observed that the retirement pension should be higher than unemployment benefits in order to have workers migrating from unemployment to retirement, although pensions do not necessarily have to be higher than wage rates to have flows of workers moving from employment to retirement. We also showed that as retiring and leaving the labour market becomes easier, wage rates and job creation flow dynamics tend to be slower.

\section{References and Notes}

1 See Gruber and Wise ${ }^{2}$ and references therein on effects of social security programmes in optimal retirement rule.

2 Gruber, J. and Wise, D. (2005) 'Social security programs and retirement around the world: Fiscal implications, introduction and summary', National Bureau of Economic Research, Working paper; 11290, Cambridge.

3 See Bound et al., ${ }^{4}$ Fields and Mitchell, ${ }^{5}$ Flippen and Tienda ${ }^{6}$ and Johnson and Neumark ${ }^{7}$ for more on these issues.

4 Bound, J., Schoenbaum, M. and Waidman, T. (1995) 'Race and education differences in disability status and labor force attachment in the health and retirement study', Journal of Human Resources, Vol. 30, No. 5, pp. 227-267.

5 Fields, G. S. and Mitchell, O. S. (1984) 'Economic determinants of the optimal retirement age: An empirical investigation', Journal of Human Resources, Vol. 14, pp. 245-262.

6 Flippen, C. and Tienda, M. (2000) 'Pathways to retirement: Patterns of labor force participation and labor market exit among the pre-retirement population by race, hispanic origin and sex', Journal of Gerontology, Vol. 55, No. 1, pp. 14-27.

7 Johnson, R. W. and Neumark, D. (1997) 'Age discrimination, job separations, and employment status of older workers: Evidence from self-reports', Journal of Human Resources, Vol. 32, No. 4, pp. $779-811$.

8 Ljungqvist and Sargent ${ }^{9}$ argued that the increase in European unemployment rate is the result of increasing economic turbulence in the last 80 years. 
9 Ljungqvist, L. and Sargent, T. (1998) 'The European unemployment dilemma', Journal of Political Economy, Vol. 106, No. 3, pp. 514-550.

10 Banco de Portugal (2004) 'Relatório de Estabilidade Financeira', Banco de Portugal, Lisboa.

11 According to Anderson et al., ${ }^{12}$ nearly 40 per cent of retirement decisions are redefined because of unexpected events. Pang et al. ${ }^{13}$ verified that in the United States, higher incomes result in higher migration to reform. According to these authors, workers who suffer high financial losses have lower chances of retiring.

12 Anderson, K. H., Burkhauser, R. U. and Quinn, J. F. (1986) 'Do retirement dreams come true? The effect of unanticipated events on retirement plans', Industrial and Labor Relations Review, Vol. 39, No. 4, pp. 518-526.

13 Pang, G., Warshawsky, M. and Weitzer, B. (2008) 'The retirement decision: Current influences on the timing on retirement among older workers', Pension Research Council, Working paper; 04, Philadelphia.

14 Some examples are Anderson et al., ${ }^{12}$ Burtless, ${ }^{15}$ and Williamson and McNamara ${ }^{16}$.

15 Burtless, G. (1986) 'Social security, unanticipated benefit increases, and the timing of retirement', Review of Economic Studies, Vol. 53, No. 5, pp. 781-805.

16 Williamson, J. B. and McNamara, T. K. (2002) 'The effect of unplanned changes in marital and disability status: Interrupted trajectories and labor force participation', Center for Retirement Research, Working paper; 2002-05, Boston College, Cambridge.

17 In this paper, we shall see the benefits generated with this model.

18 Bhattacharya, J., Mulligan, C. B. and Reed III, R. R. (2004) 'Labor market search and optimal retirement policy', Economic Inquiry, Vol. 42, No. 4, pp. 560-571.

19 According to Flippen and Tienda ${ }^{6}$ unemployment is one of the key factors that make workers leave the labour market. This happens due to the difficulties unemployed workers face when trying to find a new position.

20 Gordon, R. H. and Blinder, A. S. (1980) 'Market wages, reservation wages, and retirement decisions', Journal of Public Economics, Vol. 14, No. 2, pp. 277-308.
21 This hypothesis has been largely verified in empiric literature. See Fields and Mitchell ${ }^{5}$ for more on this.

22 Note that as we are only interested in explaining the flow of workers to retirement, we can see the present model as an analysis of a particular segment of the labour market, where every worker has just earned his right to retire.

23 Observe that the right to retire affects employment and unemployment options positively due to the increase in worker outside options that it creates. See Pissarides ${ }^{24}$ for details. Fields and Mitchell ${ }^{5}$ verified that higher wealth levels (lower obligations), result in greater retirement probabilities.

24 Pissarides, C. (2000) 'Equilibrium Unemployment Theory', MIT Press, Cambridge.

25 If we eliminated this previous condition, firms would know the right rate at which workers leave the labour force, that is, we would have $G(S)=\varphi$.

26 Hayward et al. ${ }^{27}$ and Diamond and Hausman ${ }^{28}$ verified this effect.

27 Hayward, M., Friedman, S. and Chen, H. (1998) 'Career trajectories and older men's retirement', Journals of Gerontology: Psychological and Social Sciences, Vol. 53, No. 2, pp. 91-103.

28 Diamond, P. and Hausman, J. (1984) 'The retirement and unemployment behavior of older men', in Aaron, H. and Burtless, G. (eds), 'Retirement and Economic Behavior', The Brookings Institution, Washington.

29 It is enough to compare the present model with any other one excluding the right to retire to see this result.

30 Saas $^{31}$ and Eschtruth and Gemus ${ }^{32}$ confirm this result for the United States.

31 Saas, S. (2003) 'Reforming the U.S. retirement income system: The growing role of work', Center for Retirement Research, Issues in Brief, gib_1, Cambridge.

32 Eschtruth, A. and Gemus, J. (2003) 'Are older workers responding to the bear market', Center for Retirement Research Boston College, Just the Facts, jtf-5, Cambridge.

33 As the present model only considers workers with retirement rights, we could see $b$ as the rate at which an unemployed worker receives his right to retire, which in our model is considered as unemployment rate. 